cusses just as realistically the problems presented by radiation and the disposal and treatment of radioactive wastes, which constitute both an additional cost in nuclear power and a physical problem of which the magnitude alone is as yet barely appreciated. To such problems and to the political problems of disarmament Dr. Goldschmidt returns in his last chapter, and here, as throughout the book, it does not need Sir John Cockcroft's preface to indicate that Dr. Goldschmidt writes with the authority of intimate knowledge and experience in the international as well as the national field. His competence is manifest on almost every page and is joined with a felicity of expression, faithfully reproduced in Mr. Peter Beer's translation, that makes for easy and even fascinating reading. The possibilities which nuclear energy has opened up for mankind are soberly and realistically appraised, as are the limitations involved and the price that has to be paid. Nothing short of general disarmament can avert the threat of mass destruction, and to enjoy the benefits of nuclear power and its concomitant advantages of radioactive isotopes man must accept the stern challenge of finding some means to limit national sovereignty and eliminate the threat of war.

R. Brightman

\section{CHEMISTRY AND THE ARTS}

\section{Analysis of Ancient Metals}

By Prof. Earle R. Caley. (International Series of Monographs on Analytical Chemistry, Vol. 19.) Pp. xi+176. (London and New York: Pergamon Press, 1964.) 70s. net.

$\mathrm{A}^{\mathrm{T}}$ first sight there is no reason to believe that analytical techniques applied to archaeology and the arts should differ from the procedures of classical chemistry. However, when the peculiar requirements of the archaeologist and museum curator (such as the fact that no damage may be permitted) are considered, it becomes evident that only certain methods are applicable. Some four years ago Dr. Aitken gave us a book entitled Physics and Archaeology, now Prof. Caley fills in the gap admirably and considers what the analytical chemist has to offer to the world of archaeology; unfortunately he limits his book to the consideration of metals alone, and although this is an important aspect, by far the most important conclusions have been reached by the analysis of other archaeological material such as ceramics.

Prof. Caley has had much experience in the analysis of ancient metals, and this has brought him into close contact with archaeologists. In his book he points out the very real problems involved in explaining the significance of results to the non-scientist. We hear much about bridging the gap between the two cultures, but only those actually engaged in the operation can know just how far apart are the two different methods of approaching a problem, let alone the actual ignorance of each other's subject, particularly in the case of the non-scientist knowing the chemist's jargon. Prof. Caley also points out the pitfalls which the scientist must be careful to avoid; in particular the heterogeneity of ancient metals due to corrosion, surface enrichment or previous restoration is discussed in some detail.

The main portion of the book is devoted to describing the methods of analysis best suited to each type of ancient metal object-gold, silver, copper, iron and their alloys are given special attention, while the other metals known in the ancient world, in particular lead and tin, are adequately covered. Both rapid qualitative and accurate quantitative techniques are described on the macro and somi-micro scales. Major, minor and trace elements are covered. The methods described in detail are wet chemical methods, most of which require moderately large samples. It would seem that these are well suited to large metal objects where a small hole into the body of the metal (to avoid contamination of the sample from corrosion or an unrepresentative sample from surface enrichment) would not distress the museum curator. However, the numismatist in the coin room is quite a different matter; he is particularly fussy, and even the most minute damage to a reasonably well-preserved coin is generally unthinkable. By the number of analyses quoted in his book it would soem that Prof. Caley is in touch with an unusually broad-minded museum, and indeed it is entirely rational that limited damage should be permitted to such material if such studies are going to broaden knowledge as a whole.

Perhaps, however, this brings us to a point where Prof. Caley's book is a little weak. Essentially non-destructive methods are important and little space is given to them. Although considerable space is given to the somewhat dubious specific gravity method of assay of gold and silver objects, no detailed description of neutron activation or $\mathrm{X}$-ray fluorescence is provided. Recent advances in these techniques obviate some of the objections raised by the author against thom. For example, the advent of the milliprobe X-ray spectrometer which uses a $100-\mu$ fluorescent source and bent crystal geometry spectrometer means that the disadvantages of awkward shape disappear and the errors inherent in surface enrichment may be prevented by scraping a minute area. Also some objections to neutron activation and $\gamma$-ray spectrometry have disappeared since the advent of lithium drifted silicon detectors where the resolution of spectrometers has been improved some ten-fold. The use of emission spectrometry has, on the other hand, been given adequate space and short descriptions of the most useful methods are given.

The book ends with an excellent chapter on the preparation of reports, attention being directed again to the special problems involved in writing for non-scientists. Some indication is also given of the type of conclusion which may be drawn from analytical results. Explanations of external appearance, methods of manufacture in the ancient world, evidence of trends in economic conditions and detection of forgeries are all subjects which may be forwarded by this type of investigation.

However, one of the objects of analysis is often to tie up the provenance of metals and to try and find evidence for trade between different communities. The evidence quoted in this book for such tie-ups only strengthens the belief held by many people that in the case of metals only very rarely are such archaeological conclusions possible. Because of the crudeness of the smelting operations, and the practice of remelting scrap, the composition of even closely related objects is very variable. E. T. HaIL

\section{ADHESION AND THERMAL DEGRADATION OF HIGH POLYMERS}

Autohesion and Adhesion of High Polymers

By S. S. Voyutskii. Translated from the Russian by S. Kaganoff. Translation Editor: V.L. Vakula. (Polymer Reviews, Vol. 4.) Pp. xiv + 272. (New York and London: Interscience Publishers, a Division of John Wiley and Sons, Inc., 1963.) 115s.

Thermal Degradation of Organic Polymers

By Samuel L. Madorsky. (Polymer Reviews, Vol. 7.) Pp. xiv +315 . (New York and London: Interscience Publishers, a Division of John Wiley and Sons, Inc., 1964.) $94 s$.

THE books by Prof. S. S. Voyutskii and Dr. S. L. Madorsky have certain aspects in common. Like other volumes in this series, they are concerned with fields of polymer science which are in process of rapid develop. ment. Both subjects have important scientific and technological implications. Application of basic principles 